\title{
Cyclic Load Responses of GFRP-Strengthened Hollow Rectangular Bridge Piers
}

\author{
Junfeng Jia, ${ }^{1,2}$ Qiang Han, ${ }^{1,2}$ Zigang Xu, ${ }^{1,2}$ and Dongjie Zhang ${ }^{1,2}$ \\ ${ }^{1}$ Key Laboratory of Urban Security and Disaster Engineering of Ministry of Education, Beijing University of Technology, \\ No. 100 Pinleyuan, Beijing 100124, China \\ ${ }^{2}$ Beijing Collaborative Innovation Center for Metropolitan Transportation, No. 100 Pinleyuan, Beijing 100124, China
}

Correspondence should be addressed to Qiang Han; qhan@live.com

Received 22 May 2014; Revised 12 September 2014; Accepted 15 September 2014; Published 13 October 2014

Academic Editor: Jiangbo Sha

Copyright ( $(2014$ Junfeng Jia et al. This is an open access article distributed under the Creative Commons Attribution License, which permits unrestricted use, distribution, and reproduction in any medium, provided the original work is properly cited.

\begin{abstract}
This study investigated the seismic behavior of glass fiber reinforced polymer (GFRP) strengthened hollow rectangular bridge piers. Cyclic testing of reinforced concrete (RC) piers retrofitted with GFRP was carried out under constant axial loading and lateral bending. The failure characteristics, flexural ductility, dissipated energy, and hysteretic behaviors, were analyzed based on experimental results. A simplified GFRP-confined concrete model is developed by considering effective strength coefficient and area distribution ratio of GFRP sheets. The results indicate that the failure modes and damage region would be changed and the ductility and dissipated energy of the GFRP-strengthened hollow rectangular bridge piers were improved greatly but not much improvement for the lateral load capacity. The analytical results of the force-displacement hysteretic loops based on the GFRP-confined concrete model developed in this paper agreed well with the experimental data.
\end{abstract}

\section{Introduction}

Hollow reinforced concrete (RC) bridge piers of rectangular cross section have been widely used in engineering practice, especially for bridge piers with high elevations. Hollow bridge piers can be the solution to maximize an optimal strength/mass ratio and stiffness/mass ratio for bridges in seismic regions, to reduce the mass contribution of the pier to seismic response, and also to reduce the tendency for thermally induced cracking at an early age resulting from heat-of-hydration temperature variations. A large number of existing bridges were designed in accordance with old Chinese code for seismic design of bridges [1] which are not cover specific problems related to hollow section. However, recent earthquakes such as Wenchuan earthquake (M8.0, 2008), Yushu earthquake (M7.1, 2010), and Lushan earthquake (M7.0, 2013) in China have repeatedly demonstrated the vulnerabilities of existing RC bridge piers, especially that hollow section bridge piers were damaged seriously $[2,3]$ because of insufficient low ductility or flexural strength or shear capacity. Currently, fiber reinforced polymer (FRP) is widely used for retrofitting concrete structures, but safety implication of using FRP materials is important issue in moderate and high seismicity regions on the Chinese seismic hazard map because ductility and shear capacity of these columns vary with the type of lateral reinforcement. Generally, in order to avoid catastrophic fragility failure of bridge structure system, it is desired to dissipate energy by postelastic deformation in potential plastic hinge region of bridge pier. However, FRP materials are generally known for their linear elastic response to failure, so it is important to evaluate the seismic behavior of GFRP-concrete bridge piers under inelastic cyclic loading [4].

Many retrofit techniques have been proposed such as steel jacketing and composite jacketing which provide confinement for RC bridge piers. FRP can significantly improve the flexural and shear strengths and increase the ductility of the RC pier, as proposed by some researchers [5-8]. Some test results [9-11] reported that both ductility and shear strength increased with the thickness of FRP jacket, preventing all 
shear cracks and changing the failure mode of the specimen from shear to flexure. Recently, extensive studies on concrete confined with large rupture strain FRP composites, FRP strengthened concrete-filled steel tubular stub piers, were conducted [11-13]. Although glass fiber reinforced polymer (GFRP) has a lower elastic modulus and tensile strength than carbon fibers, its high deformability, good impact, and break resistance properties turn them into a good material for strengthening [14-18]. Moreover, the seismic behavior of high-strength concrete columns confined by fiber reinforced polymer tubes was discussed, which is focused on the influence factors on the seismic behavior of the columns $[19,20]$. However, there is a lack of information of seismic behavior of GFRP-strengthened RC piers, especially RC hollow section bridge piers retrofitted with GFRP.

Cyclic tests of six pier specimens were performed under constant axial load with lateral bending to investigate the seismic performance of GFRP-strengthened RC hollow rectangular bridge piers in this paper. The main objectives in this paper are (1) to develop an effective repair technique and to evaluate the feasibility of using GFRP as external reinforcement for RC hollow rectangular bridge piers, (2) to evaluate seismic capacity of hollow bridge piers retrofitted with GFRP in terms of performance-based seismic design philosophy, and (3) to develop a simplified GFRP-confined concrete model for predicting nonlinear lateral load versus displacement hysteresis behavior of GFRP-strengthened RC hollow rectangular bridge piers.

\section{Experimental Schemes}

2.1. Overview. Six hollow RC piers were designed and tested under a combination of constant axial load and cyclic lateral bending, as shown in Figure 1. The six specimens were divided into two test groups by slenderness ratio of $L / b=$ 4 or $L / b=8$. The height of the specimens (the vertical distance between the horizontal actuator loading point and the top of the RC footing) is $1.4 \mathrm{~m}$ and $2.8 \mathrm{~m}$, respectively. The cross section dimensions and wall thickness of specimen are, respectively, $550 \mathrm{~mm} \times 350 \mathrm{~mm}$ and $110 \mathrm{~mm}$. The key properties of the specimens are listed in Table 1 . The bridge pier specimens retrofitted with circular reinforcement were wrapped by two or three layers of GFRP sheets within the bottom of $500 \mathrm{~mm}$. In addition, in order to compare the seismic performance of RC hollow rectangular bridge piers with and without GFPR sheets, the reversed cyclic tests of two control model pier specimens were conducted under the same loading scheme.

2.2. Material Properties. The average measured values of the yielding strength, ultimate stress, and ultimate strain of reinforcing steel coupons from standard tensile tests were $435 \mathrm{MPa}, 498 \mathrm{MPa}$, and 13\%, respectively. The actual average compressive strength of concrete was $f_{c}^{\prime}=30.4 \mathrm{MPa}$, which was determined by compression tests on typical $150 \times 150 \times$ $150 \mathrm{~mm}$ cubic compression test after 28-day curing process. Both the measured reinforcing steel and concrete strengths were higher than the design strengths. The mechanics properties of GFRP and saturant are listed in Tables 2 and 3, respectively.

2.3. Loading Protocol and Setup. Each specimen was mounted vertically on a strong floor and subjected to an axial load on the top as well as bending load by lateral actuator. The constant axial load is $0.2 A_{g} f_{c}^{\prime}$, where $A_{g}$ is the gross cross sectional area of piers and $f_{c}^{\prime}$ is the concrete compressive design strength. The lateral actuator has a capacity of $1000 \mathrm{kN}$ and is capable of moving the bridge pier head the range from $-150 \mathrm{~mm}$ to $+150 \mathrm{~mm}$, with the maximum value corresponding to $5.4 \%$ and $10.8 \%$ drift ratio for $L / b=8$ or $L / b=4$ test pier, respectively. Based on different drift or displacement requirements for piers with different heights, two cycles were applied at each level of the lateral displacement history.

The bridge pier specimens were extensively instrumented for monitoring the following: (a) global response quantities (e.g., applied lateral load and displacement), (b) local response quantities (e.g., steel bar strains and curvatures in the potential plastic hinge zone of test piers), and (c) extent of damage and remaining capacity of the piers. The curvature over the plastic hinge zones was obtained using five calibrated linear variable differential transformers (LVDTs) of the pier specimen. Five wire-type displacement transducers were used to measure the longitudinal and transverse displacements at the top- and mid-height of the pier. 36 strain gages were installed to monitor the strain evolutions of longitudinal and transverse reinforcing steel bars in the potential plastic hinge zones.

\section{Experimental Results}

3.1. General Observations. Failure modes of $L / b=4$ and $L / b=8$ specimens under constant axial load and cyclic lateral bending are shown in Figure 2. The damage progression and failure mode of control specimens SU-1 and SH-1 were similar to common flexural-shear and flexural types bridge piers (shown in Figures 2(a) and 2(d)), respectively. The most notable observations, in sequence of occurrence, were concrete cracking, longitudinal reinforcement yielding, spalling of concrete, and longitudinal reinforcement buckling.

The failure modes and damage region of the specimens wrapped with GFRP sheets were changed. Slight concrete spalling and buckling of longitudinal steel bars were observed at the bottom of the pier $(L / b=4)$; no visible fiber rupture of GFRP sheets was observed during the test, resulting in reduction of concrete damage, the degree of which reduces with the increase of the GFRP layers.

Comparing the damage position of short piers $(L / b=4)$ and higher piers $(L / b=8)$ retrofitted with GFRP sheets, the failure modes of control specimens are typical flexural failure. Plastic hinge regions were fully formed at the bottom of the columns, which contributed to the development of ductility. With the increasing of the GFRP cloth ratio, the plastic hinge region would be changed from the bottom of the columns to the relatively higher region of the column with the increasing 


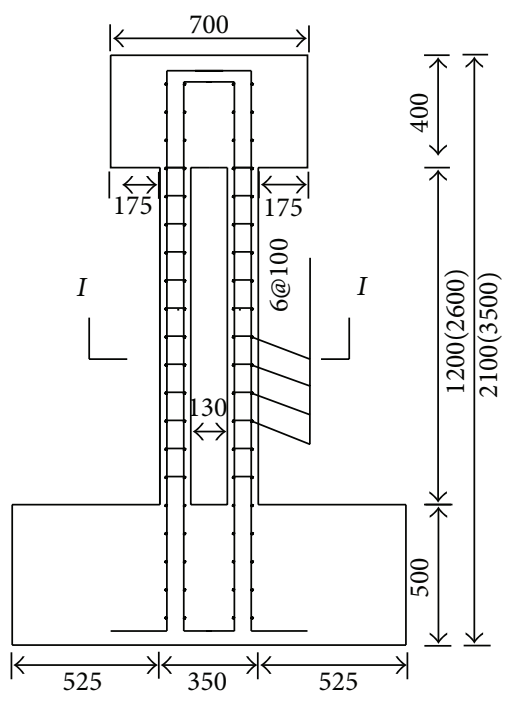

(a)

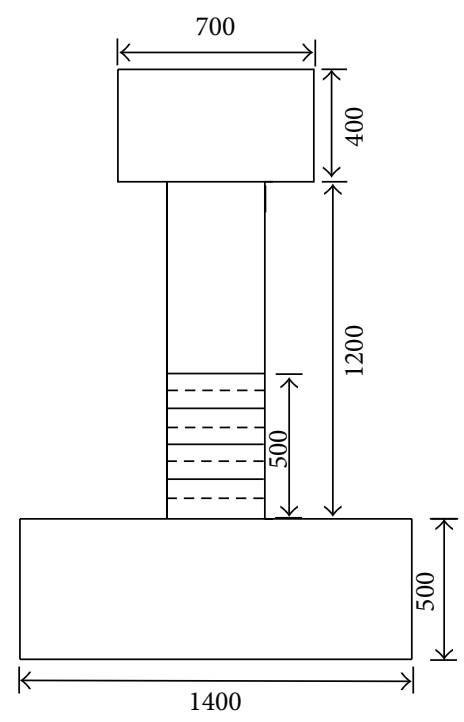

(c)

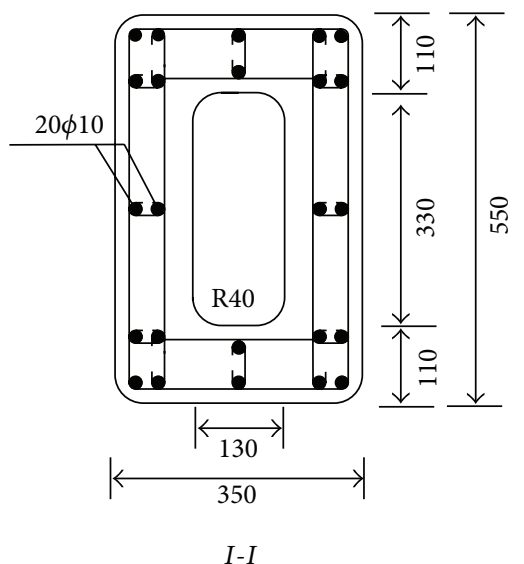

(b)

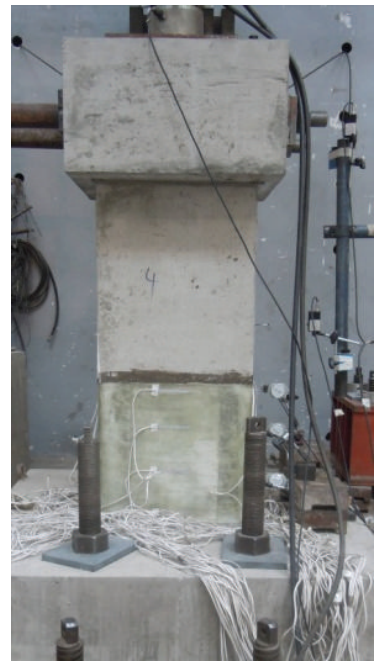

(d)

FIGURE 1: Column specimen (unit: $\mathrm{mm}$ ), (a) dimensions of specimen, (b) configurations of lateral steel (c) $L / b=8$, and (d) specimen photo.

TABLE 1: Properties of the bridge pier specimens.

\begin{tabular}{|c|c|c|c|c|c|c|c|c|}
\hline \multirow[b]{2}{*}{$\begin{array}{l}\text { Specimen } \\
\text { number }\end{array}$} & \multirow[b]{2}{*}{ Height/mm } & \multicolumn{2}{|c|}{ Longitudinal bar } & \multicolumn{2}{|c|}{ Stirrup bar } & \multirow[b]{2}{*}{$\begin{array}{l}\text { Confined } \\
\text { height } / \mathrm{mm}\end{array}$} & \multirow[b]{2}{*}{$\begin{array}{c}\text { GFRP } \\
\text { (cloth ratio) }\end{array}$} & \multirow[b]{2}{*}{$\begin{array}{c}\text { Axial load } \\
\text { ratio }\end{array}$} \\
\hline & & Diameter & $\begin{array}{c}\text { Reinforcement } \\
\text { ratio }\end{array}$ & $\begin{array}{c}\text { Diameter and } \\
\text { spacing }\end{array}$ & $\begin{array}{c}\text { Volumetric } \\
\text { ratio }\end{array}$ & & & \\
\hline SU-1 & 1400 & $20 \phi 10$ & $1.05 \%$ & $\phi 6$ at 100 & $0.49 \%$ & 0 & - & 0.2 \\
\hline SHG-2 & 1400 & $20 \phi 10$ & $1.05 \%$ & $\phi 6$ at 100 & $0.49 \%$ & 500 & 0.40 & 0.2 \\
\hline SHG-3 & 1400 & $20 \phi 10$ & $1.05 \%$ & $\phi 6$ at 100 & $0.49 \%$ & 500 & 0.61 & 0.2 \\
\hline LU-1 & 2800 & $20 \phi 10$ & $1.05 \%$ & $\phi 6$ at 100 & $0.49 \%$ & 500 & - & 0.2 \\
\hline LHG-2 & 2800 & $20 \phi 10$ & $1.05 \%$ & $\phi 6$ at 100 & $0.49 \%$ & 500 & 0.40 & 0.2 \\
\hline LHG-3 & 2800 & $20 \phi 10$ & $1.05 \%$ & $\phi 6$ at 100 & $0.49 \%$ & 500 & 0.61 & 0.2 \\
\hline
\end{tabular}

Note: (a) $S(L)$ stands for slenderness ratio $L / b=4(L / b=8)$.

(b) U denotes standard specimens without GFRP.

(c) HG denotes GFRP's sheet circular confinement, in which the number is GFRP layers.

(d) GFRP (cloth ratio): cloth ratio can be expressed by Ac/As, where Ac is the area of GFRP for each section and as is the area of cross section. 


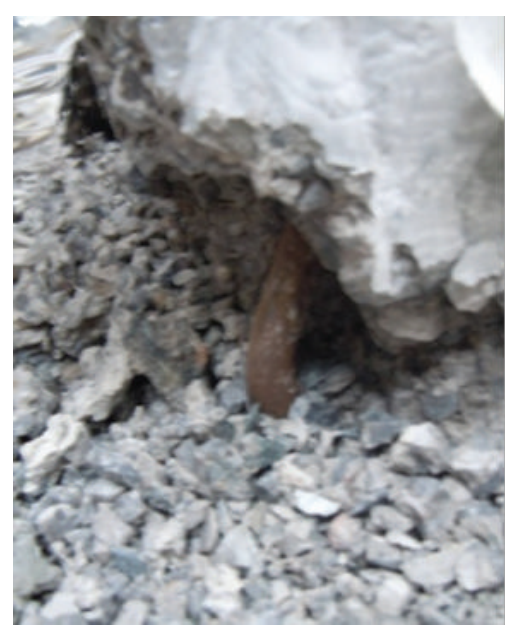

(a)

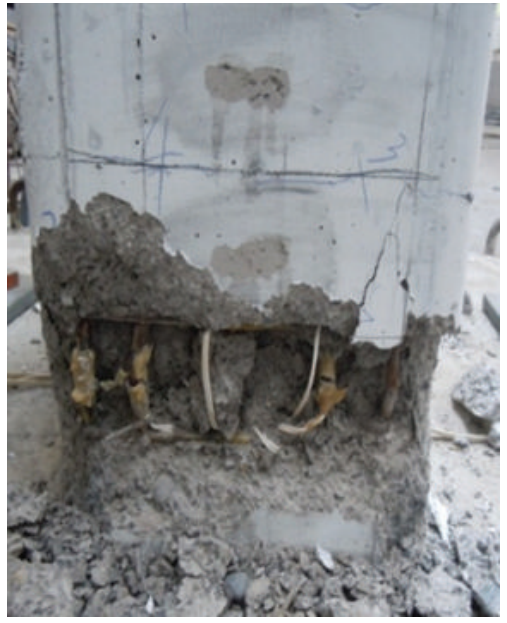

(d)

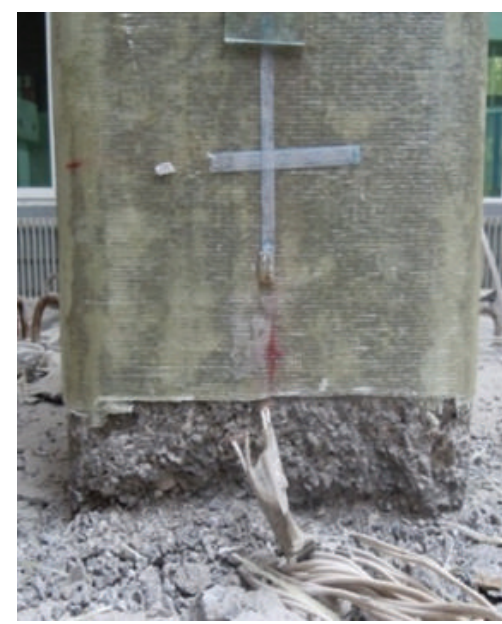

(b)

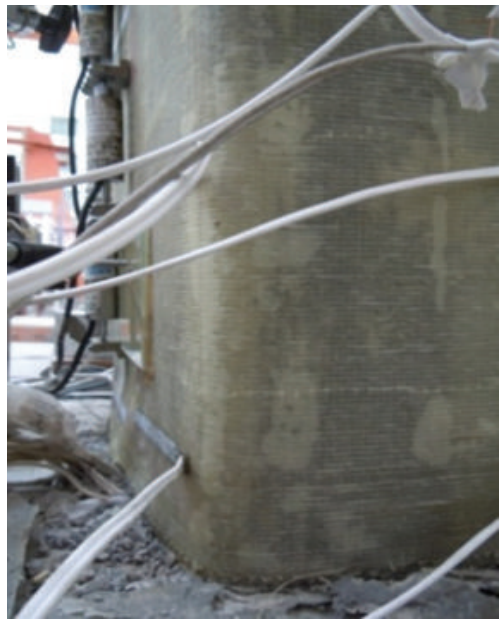

(e)

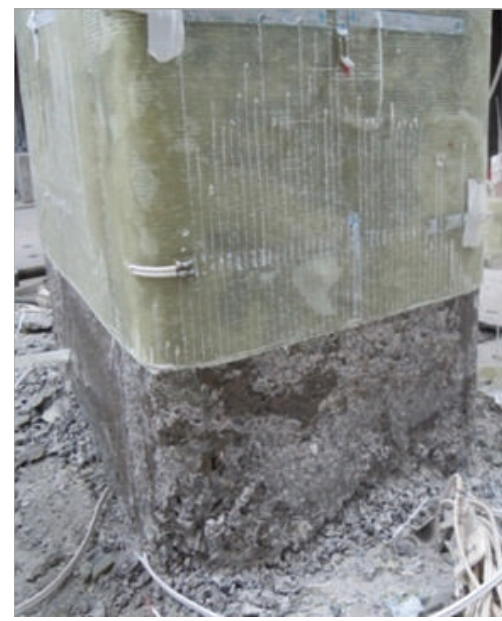

(c)

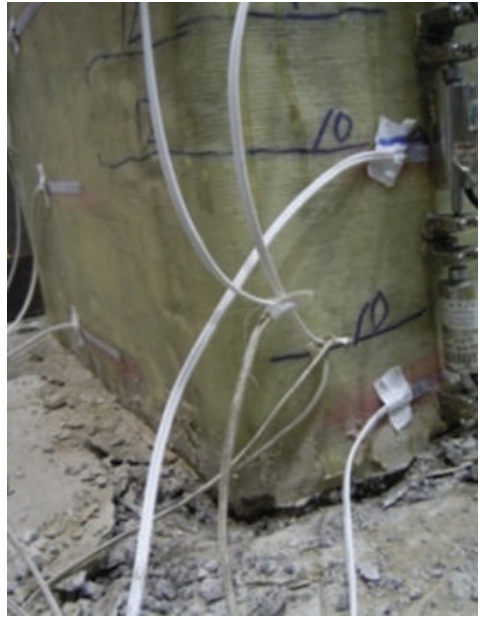

(f)

Figure 2: Failure modes of specimens (a) SU-1, (b) SHG-2, (c) SHG-3, (d) LU-1, (e) LHG-2, and (f) LHG-3.

TABLE 2: Mechanics properties of GFRP.

\begin{tabular}{lccc}
\hline $\begin{array}{l}\text { Mass per area } \\
\left(\mathrm{g} / \mathrm{m}^{2}\right)\end{array}$ & $\begin{array}{c}\text { Nominal thickness } \\
(\mathrm{mm})\end{array}$ & $\begin{array}{c}\text { Tensile strength } \\
(\mathrm{MPa})\end{array}$ & $\begin{array}{c}\text { Elasticity modulus } \\
(\mathrm{GPa})\end{array}$ \\
\hline 430 & 0.169 & 2227 & 104 \\
\hline
\end{tabular}

TABLE 3: Mechanics properties of saturant.

\begin{tabular}{lccc}
\hline $\begin{array}{l}\text { Concrete normal bonding strength } \\
(\mathrm{MPa})\end{array}$ & $\begin{array}{c}\text { Tensile strength } \\
(\mathrm{MPa})\end{array}$ & $\begin{array}{c}\text { Elasticity modulus } \\
(\mathrm{MPa})\end{array}$ & $\begin{array}{c}\text { Ultimate tensile strain } \\
(\%)\end{array}$ \\
\hline 3.12 & 51.1 & 2569 & 1.91 \\
\hline
\end{tabular}

of the GFRP cloth ratio. Meantime, the failure mode may be change from typical flexural failure to flexural-shear failure.

3.2. Lateral Load-Displacement Hysteretic Response. The testing results of load-displacement hysteresis curves of the specimens are presented in Figures 3 and 4. Retrofitted piers and control piers hysteresis curves are shown in Figures 4(a) and 4(b). In the elastic stage, the area bounded by the hysteresis curves was relatively small. With the increasing of lateral displacement, specimen piers worked in the elastoplasticity phase and lateral bearing capacity enhanced little. Meanwhile, the stiffness of the specimens was reduced significantly. After the peak load, the descending branch was not much severe for the retrofitted piers compared to the control piers. The cycle time and the ultimate displacement of the retrofitted piers increased in the condition of maintaining the same horizontal bearing capacity, which indicates that 

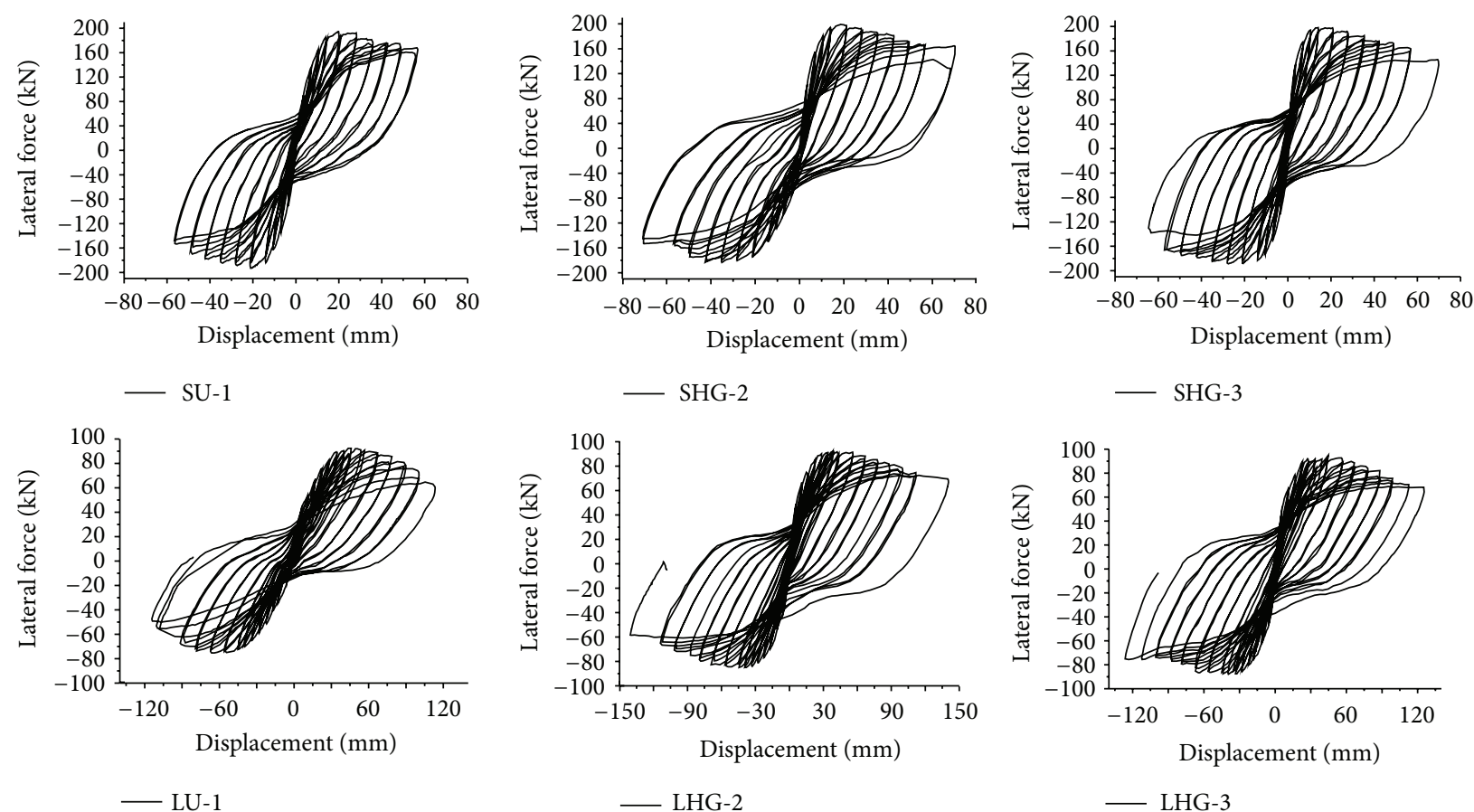

Figure 3: Lateral force-displacement hysteresis loops of specimen.

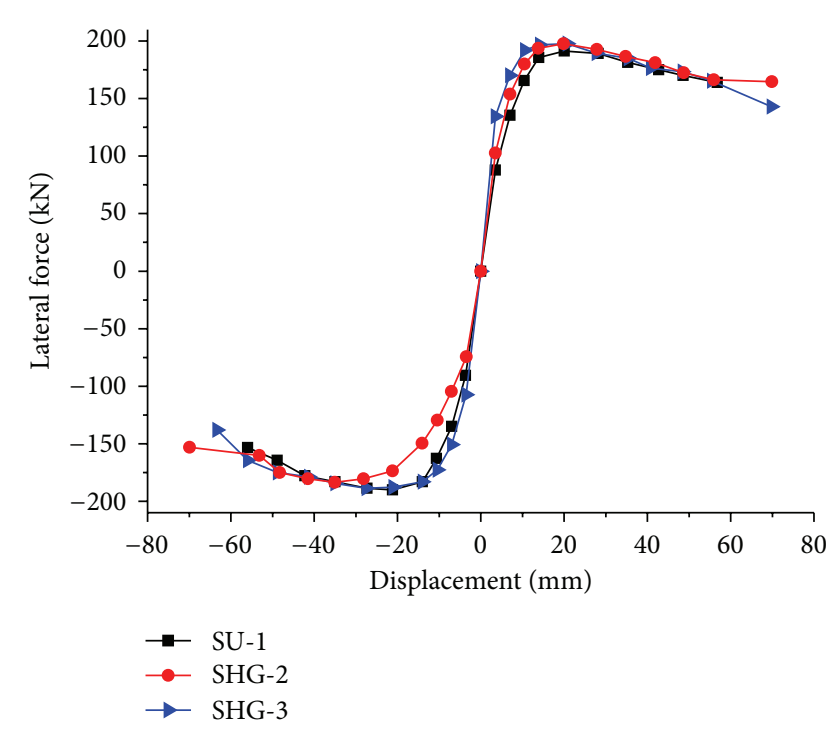

(a)

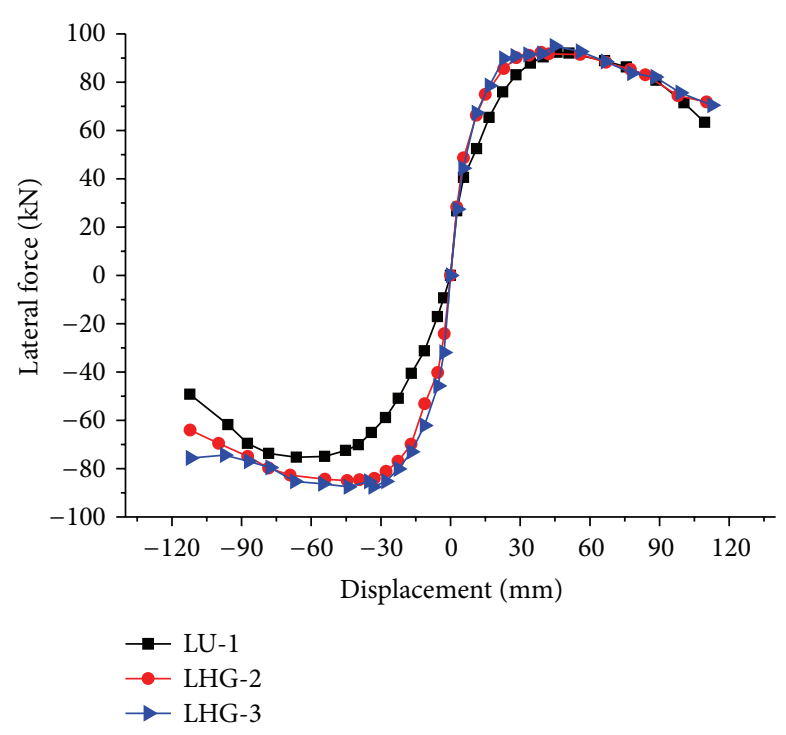

(b)

FIgURE 4: Skeleton curves of specimens (a) $L / b=4$ and (b) $L / b=8$.

the retrofitted piers have better capacities of ductility and deformation. When the ultimate displacement was reached or exceeded, the pinching effect was more severe for $L / b=4$ retrofitted piers due to the developing of concrete cracks, bonding-slip between concrete, and reinforcing bars, as well as debonding failure of GFRP-concrete interface.

3.3. Ductility and Bearing Capacity. The displacement ductility factor is defined as the displacement corresponding to $80 \%$ of the maximum lateral load (in the descending portion of the horizontal load-displacement curve) divided by the yield displacement [21]. The yield displacement of a pier is defined as the displacements corresponding to the yield of a longitudinal steel bar measured by strain gauges. The maximum lateral forces, the ultimate lateral forces, and the ultimate lateral displacements in both push and pull directions are shown in Table 4.

Table 4 shows that the displacement ductility coefficient of $L / b=4$ GFRP retrofitted piers SHG-2 and SHG3 increased by 0 and $42.5 \%$, respectively. Similarly, as for 


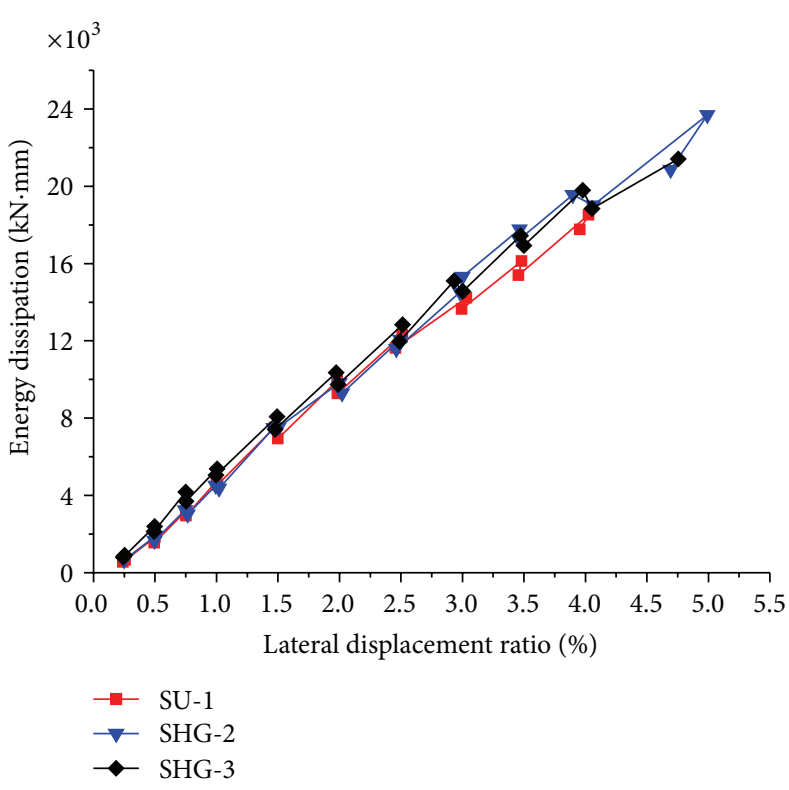

(a)

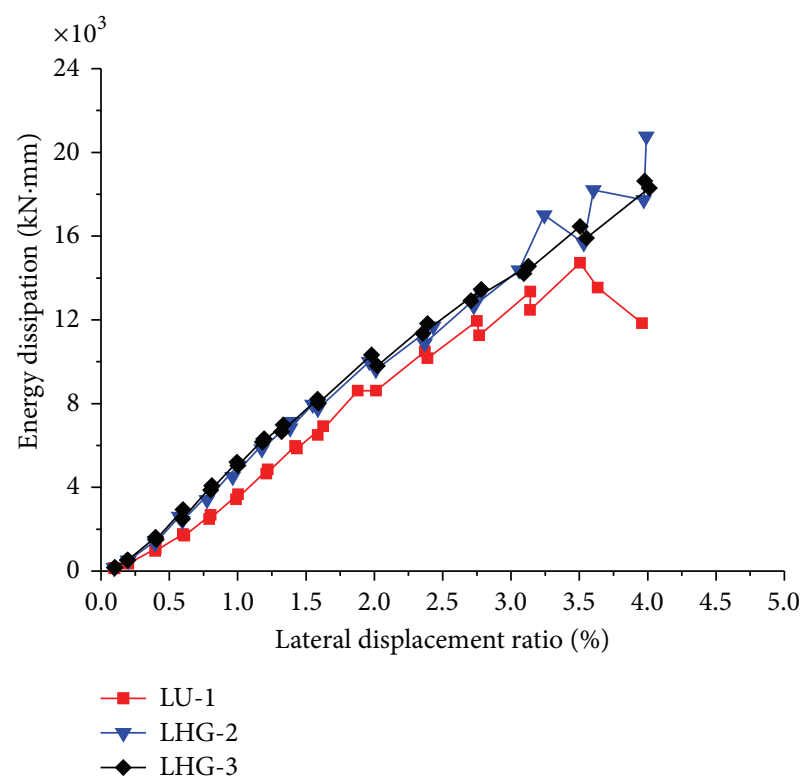

(b)

FIGURE 5: Comparison of energy dissipation.

$L / b=8$ piers, LHG-2 and LHG-3 increased by $77.4 \%$ and 93.6\%, respectively. From Table 4 , it is clearly shown that the maximum lateral load for $L / b=8$ retrofitted piers LHG- 2 and LHG-3 increased by $5.8 \%$ and $7.5 \%$, respectively, under the same axial compression ratio. As for the $L / b=4$ retrofitted piers, the increase of the maximum lateral load was approximately $3.0 \%$. Thus the strengthened hollow rectangular bridge piers with GFRP sheet significantly improve the ability of energy dissipation and ductility but not much improvement for lateral load capacity was achieved.

3.4. Energy Dissipation. The dissipated energy in one hysteresis loop $\left(W_{i}\right)$ is determined by calculating the area enclosed by the hysteresis loop as indicated by $(1) . F_{l}(u)$ and $F_{u l}(u)$ are the forces at displacement $u$ during loading and unloading process. The accumulative energy dissipated in the pier specimens is the area enclosed by all hysteresis loops:

$$
\Delta W_{i}=\int_{-v_{\min }}^{v_{\max }}\left(F_{l}(u)-F_{u l}(u)\right) d u .
$$

The comparisons of energy dissipation are listed in Figure 5 and the accumulated dissipated energy is shown in Table 4. Test results show that the accumulated dissipated energy of $L / b=4$ retrofitted piers SHG-2 and SHG-3 increased by $15.9 \%$ and $18.6 \%$; also, $L / b=8$ retrofitted piers LHG2 and LHG-3 increased by $32.6 \%$ and $32.0 \%$, respectively. The retrofitted RC piers show excellent energy dissipation capacity that is higher than common RC hollow section piers, which meets the specified seismic design and retrofit requirement of concrete structures in China.

3.5. Stiffness Degradation. The phenomenon that the stiffness of piers decreased as the load-displacement increases is defined as stiffness degradation. Figure 6 expresses the lateral stiffness and drift ratio of the test piers. The stiffness degrades in both strong axis and weak axis, and the stiffness deterioration process in both directions follows similar paths. The specimen stiffness decreased as the lateral displacement increased. As the specimen turned into yielding region and reached the maximum resistance, the stiffness degradation of the specimen was stabilized. The explanation of stiffness degradation is that concrete cracks widen and the cracked concrete loses its functionality. Besides, slip of concreteCFRP sheet interfaces occurs, leading to gradual decrease of the effective cross section height. As shown in Figure 6, it can be observed that (1) the initial stiffness of retrofitted piers increased obviously with the increase of FRP thickness. For identical GFRP wrapping rate, the maximum initial stiffness increased by $37.9 \%$ and $59.7 \%$ for piers with $L / b=4$ and $L / b=$ 8 , respectively, (2) compared with retrofitted piers with $L / b=$ 4 , the yield stiffness of piers with $L / b=8$ increased larger and the maximum value increased by $96.1 \%$ because yield load increases and yield displacement appears earlier, and (3) the increase of ultimate stiffness with $L / b=8$ retrofitted piers indicates that GFRP effective constrain effect delays the failure of the core concrete. The descending of ultimate stiffness with $L / b=4$ retrofitted piers is the fact that crushed concrete spalls more severe than of $L / b=8$ retrofitted piers, thus weakening the restraining effect of GFRP sheets.

\section{Analytical Modeling}

4.1. Modeling of Rebar. The Giuffré-Menegotto-Pinto model [22] was adopted as the constitutive model of rebar, which is described by bilinear kinematic hardening. The bilinear kinematic hardening model of rebar is composed by two straight 
TABLE 4: Experimental results.

\begin{tabular}{|c|c|c|c|c|c|c|c|c|c|c|c|}
\hline $\begin{array}{l}\text { Specimen } \\
\text { number }\end{array}$ & $\begin{array}{l}\text { Loading } \\
\text { direction }\end{array}$ & $K_{0} /(\mathrm{kN} / \mathrm{mm})$ & $F_{y} / \mathrm{kN}$ & $\Delta_{y} / \mathrm{mm}$ & $F_{m} / \mathrm{kN}$ & $\Delta_{m} / \mathrm{mm}$ & $F_{u} / \mathrm{kN}$ & $\Delta_{u} / \mathrm{mm}$ & $\begin{array}{c}\text { Accumulated dissipated } \\
\text { energy } /(\mathrm{kN} \cdot \mathrm{m})\end{array}$ & $\Delta_{u}-\Delta_{y} / \mathrm{mm}$ & $\mu_{\Delta}$ \\
\hline \multirow{3}{*}{ SU-1 } & Push & 24.74 & 165.75 & 10.46 & 191.41 & 20.05 & 162.70 & 57.51 & \multirow{3}{*}{178.80} & 47.05 & 5.49 \\
\hline & Pull & 24.92 & 160.79 & 10.34 & 190.13 & 21.17 & 161.61 & 50.67 & & 40.33 & 4.90 \\
\hline & Average & 24.83 & 163.27 & 10.40 & 190.77 & 20.61 & 162.16 & 54.09 & & 43.69 & 5.2 \\
\hline \multirow{3}{*}{ SHG-2 } & Push & 29.32 & 168.25 & 8.90 & 197.85 & 19.88 & 168.17 & 53.78 & \multirow{3}{*}{207.39} & 44.88 & 6.04 \\
\hline & Pull & 21.60 & 146.81 & 13.53 & 183.69 & 28.13 & 156.14 & 62.78 & & 49.25 & 4.64 \\
\hline & Average & 25.46 & 157.53 & 11.22 & 190.77 & 24.00 & 162.16 & 58.28 & & 47.06 & 5.20 \\
\hline \multirow{3}{*}{ SHG-3 } & Push & 37.88 & 165.87 & 6.56 & 197.83 & 20.78 & 168.16 & 53.00 & \multirow{3}{*}{212.07} & 46.44 & 8.08 \\
\hline & Pull & 30.61 & 159.03 & 8.29 & 188.82 & 27.49 & 160.50 & 57.03 & & 48.74 & 6.88 \\
\hline & Average & 34.24 & 162.45 & 7.42 & 193.33 & 24.14 & 164.33 & 55.01 & & 47.59 & 7.41 \\
\hline \multirow{3}{*}{ LU-1 } & Push & 9.89 & 67.35 & 17.79 & 92.37 & 45.91 & 78.51 & 91.40 & \multirow{3}{*}{180.50} & 73.61 & 5.14 \\
\hline & Pull & 3.15 & 64.85 & 33.85 & 75.31 & 66.32 & 64.01 & 93.42 & & 59.57 & 2.76 \\
\hline & Average & 6.52 & 66.10 & 25.82 & 83.84 & 56.12 & 71.26 & 92.41 & & 66.59 & 3.45 \\
\hline \multirow{3}{*}{ LHG-2 } & Push & 10.30 & 72.59 & 13.95 & 92.37 & 38.98 & 78.51 & 91.95 & \multirow{3}{*}{239.31} & 78.00 & 6.60 \\
\hline & Pull & 8.94 & 67.97 & 16.36 & 84.97 & 44.49 & 72.23 & 93.65 & & 77.29 & 5.72 \\
\hline & Average & 9.62 & 70.28 & 15.15 & 88.67 & 41.74 & 75.37 & 92.80 & & 77.65 & 6.12 \\
\hline \multirow{3}{*}{ LHG-3 } & Push & 9.47 & 75.36 & 15.14 & 94.97 & 44.73 & 80.72 & 90.43 & \multirow{3}{*}{238.25} & 75.29 & 5.97 \\
\hline & Pull & 11.34 & 65.50 & 12.91 & 87.56 & 43.96 & 74.43 & 97.07 & & 84.16 & 7.52 \\
\hline & Average & 10.41 & 70.43 & 14.03 & 91.27 & 44.35 & 77.57 & 93.75 & & 79.73 & 6.68 \\
\hline
\end{tabular}

Note: (a) $\Delta_{y}$ and $F_{y}$ denote yield displacement and yield force, respectively.

(b) $F_{m}$ and $\Delta_{m}$ denote maximum lateral force and corresponding displacement, respectively.

(c) $\Delta_{u}$ and $F_{u}$ stand for ultimate displacement and corresponding displacement, respectively.

(d) $\mu_{\Delta}$ denotes displacement ductility coefficient.

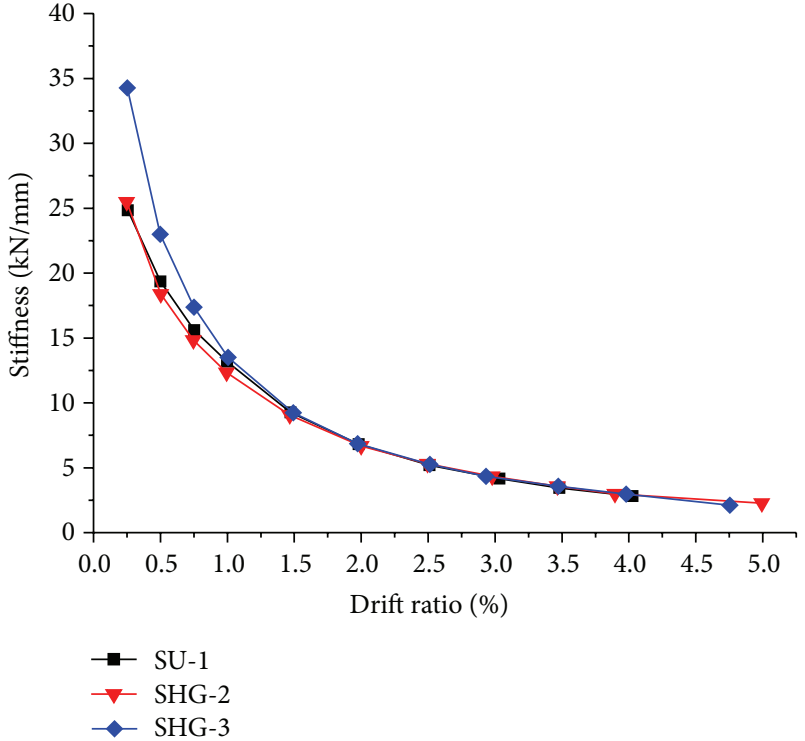

(a)

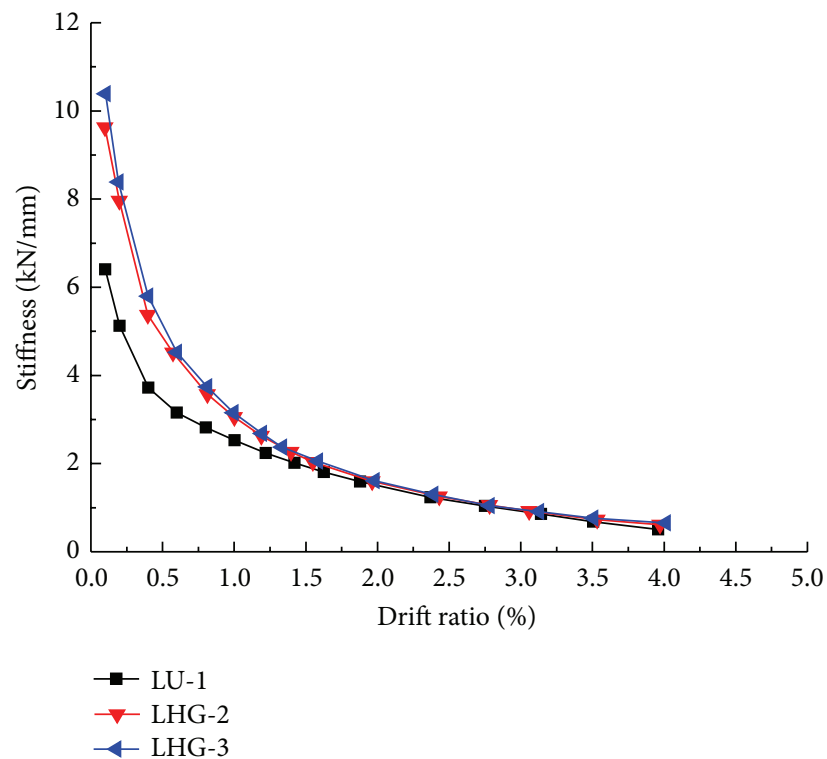

(b)

Figure 6: Curves of stiffness degradation.

lines, taking isotropic strain hardening into accounting. The formulas are shown as follows:

$$
\begin{gathered}
\sigma_{s}=E_{s} \varepsilon_{s}, \quad \varepsilon_{s} \leq \varepsilon_{y}, \\
\sigma_{s}=f_{y}+E_{s}\left(\varepsilon_{s}-\varepsilon_{y}\right), \quad \varepsilon_{s} \geq \varepsilon_{y} .
\end{gathered}
$$

4.2. Modeling of GFRP. GFRP was simplified into linear elastic material in the longitudinal direction, which corresponded to previous testing data. Therefore, it is assumed that GFRP is completely elastic material with the elasticity modulus of $245.5 \mathrm{GPa}$ in this paper. 

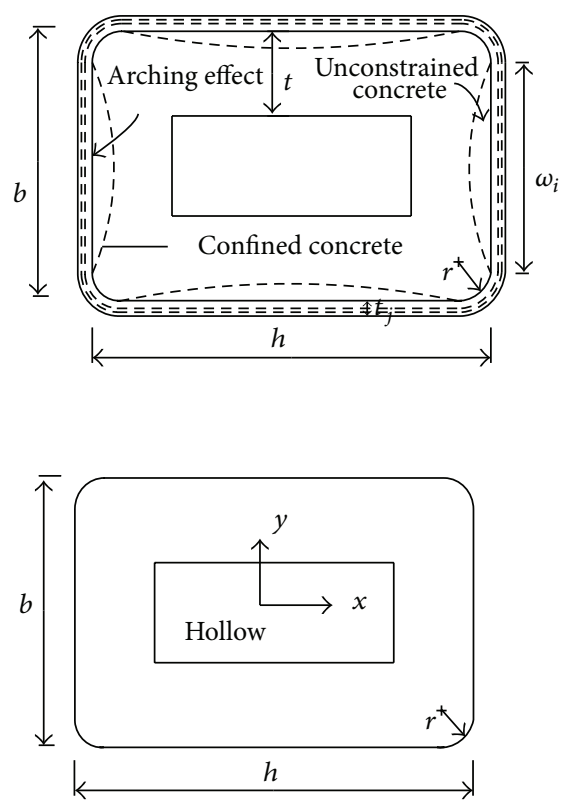

(a)

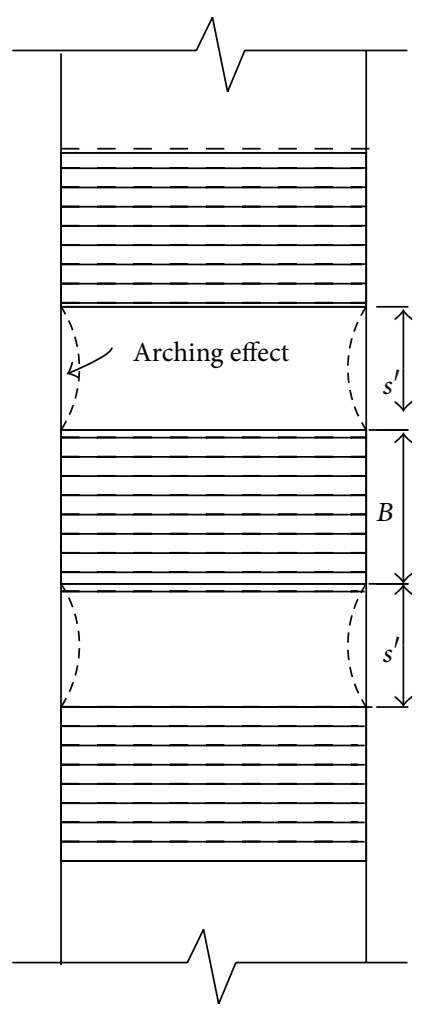

(b)

FIGURE 7: Arching effect of section (a) cross section and (b) longitudinal section.

4.3. Modeling of Concrete. The Mander confined and unconfined concrete models [23] were adopted for core concrete and cover concrete of control piers, respectively. The combined confining effect by GFRP and transversal stirrups on core concrete can be calculated by Mander confined constitutive model considering their coconstraining effect, and the Mander unconfined model for plain concrete model was adopted for cover concrete. The expression of constitutive model for confined concrete is shown as follows:

$$
f_{c}=\frac{f_{c c}^{\prime} x r}{r-1+x^{r}},
$$

where $x=\varepsilon_{c} / \varepsilon_{c c}, r=E_{c} /\left(E_{c}-E_{\mathrm{sec}}\right), E_{c}=5000 \sqrt{f_{c}^{\prime}}$, $E_{\mathrm{sec}}=f_{c c}^{\prime} / \varepsilon_{c c}, f_{c c}^{\prime}$ is peak strength of core concrete; $\varepsilon_{c c}$ is peak strain of core concrete; $f_{c}^{\prime}$ is peak strength of plain concrete; $E_{c}$ is initial elastic modulus of concrete; and $E_{\text {sec }}$ is peak secant modulus of core concrete.

The expressions of peak strength and peak strain for core concrete are shown as follows:

$$
\begin{gathered}
f_{c c}^{\prime}=f_{c}^{\prime}\left(-1.254+2.254 \sqrt{1+\frac{7.94 f_{l}}{f_{c}^{\prime}}}-2 \frac{f_{l}}{f_{c}^{\prime}}\right), \\
\varepsilon_{c c}=\varepsilon_{c o}\left[1+5\left(\frac{f_{c c}^{\prime}}{f_{c}^{\prime}}-1\right)\right],
\end{gathered}
$$

where $f_{l}$ is effective lateral confining force of core concrete.
When the RC piers were wrapped with GFRP sheets, $f_{l}$ (in Mander constitutive model for confined concrete) contains stirrups $\left(f_{\text {lsteel }}\right)$ and GFRP $\left(f_{\text {lgfrp }}\right)$ lateral confining force, where $f_{\text {lgfrp }}$ can be calculated by simplified calculating method which is proposed in the previous section:

$$
\begin{aligned}
& f_{l}=f_{l \text { steel }}+f_{\text {lgfrp }}, \\
& f_{l \text { steel }}=k_{s e} \rho_{s} f_{y h},
\end{aligned}
$$

where $k_{s e}$ is effective lateral confining force of stirrups; $\rho_{s}$ is stirrup ratio; and $f_{y h}$ is effective yield strength of stirrups.

\section{Simplified Analytical Approach for GFRP Lateral Confining Force}

The effective lateral confining force is a combined contribution from both GFRP sheets and transversal stirrups, which can enhance the ultimate compression strength and strain of core concrete. Therefore, the influence GFRP on core concrete can be considered by modified confined concrete constitutive model in numerical analysis. In order to calculate the lateral confining force of GFRP sheets, a simplified lateral confined model of GFRP is developed by considering effective strength coefficient and area distribution ratio of GFRP sheets. It is convenient for application to the confined concrete constitutive relationship in the effective GFRP lateral confining force. 


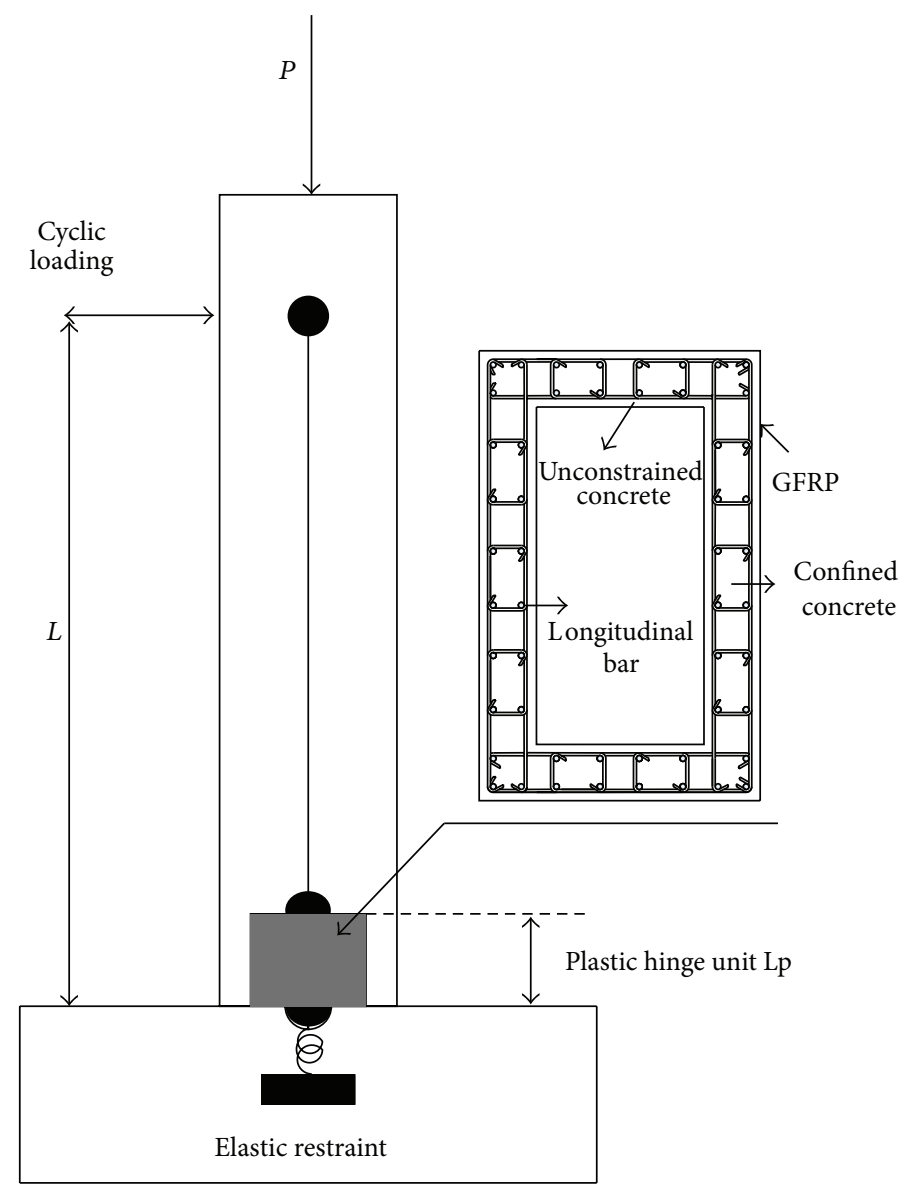

FIgURE 8: Analytical model.

Taking into account arching effect (as shown in Figure 7) of the longitudinal direction and the area stirrup ratio consisting of the effective ultimate tensile strength of the confined region, the simplified formula of the effective lateral confined force is shown as follows:

$$
f_{\text {lgfrp }(x o r y)}=k_{e}^{\prime} \rho_{\operatorname{gfrp}(x o r y)} \overline{\bar{\varepsilon}_{t}} E_{\text {gfrp }},
$$

where $k_{e}^{\prime}$ is the effective strength coefficient; $\rho_{\text {gfrp(xory) }}$ is confined area stirrup ratio of section ( $x$ or $y$ direction); $\bar{\varepsilon}_{t}$ is effective ultimate tensile strain of GFRP; and $E_{\text {gfrp }}$ is elasticity modulus of GFRP sheets.

The GFRP sheets ratio of section in $x$ and $y$ direction can be expressed as follows:

$$
\begin{aligned}
& \rho_{\text {gfrp } x}=\frac{2 t_{j}}{b}, \\
& \rho_{\text {gfrpy } y}=\frac{2 t_{j}}{h},
\end{aligned}
$$

where $t_{j}$ is thickness of CFRP sheets; $b$ is width of section; and $h$ is depth of section.
Considering the effect of section chamfering and arching effecting on core concrete area, the formula of $k_{e}^{\prime}$ is expressed as follows:

$$
\begin{gathered}
k_{e}^{\prime}=\frac{A_{e}}{A_{c}}\left(1-\frac{s^{\prime}}{2 b}\right)\left(1-\frac{s^{\prime}}{2 h}\right), \\
A_{c}=b h-(4-\pi) r^{2}-(b-2 t)(h-2 t), \\
A_{e}=A_{c}-\sum_{i=1}^{n} \frac{\omega_{i}^{2}}{6},
\end{gathered}
$$

where $A_{e}$ is effective confined concrete section area considering arching effect; $A_{c}$ is net area of section concrete; $r$ is fillet radius; $t$ is section thickness; $\omega_{i}$ is section horizontal length of $i$ th arch camber; and $s^{\prime}$ is longitudinal spacing or effective confinement spacing.

\section{Model Validation}

Hysteresis behavior of the specimens was simulated by a fiber element model using the OpenSees platform. Figure 8 shows the pier model being a cantilever pier having plastic hinge zone connected to a beam element.

A simplified analytical model is developed using OpenSees for hysteretic analysis to verify the model 


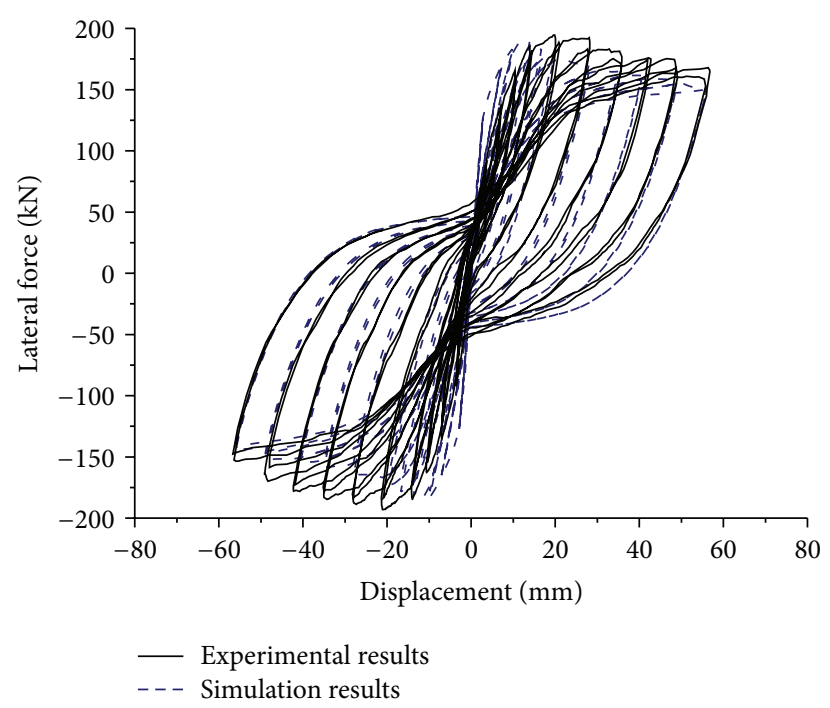

(a)

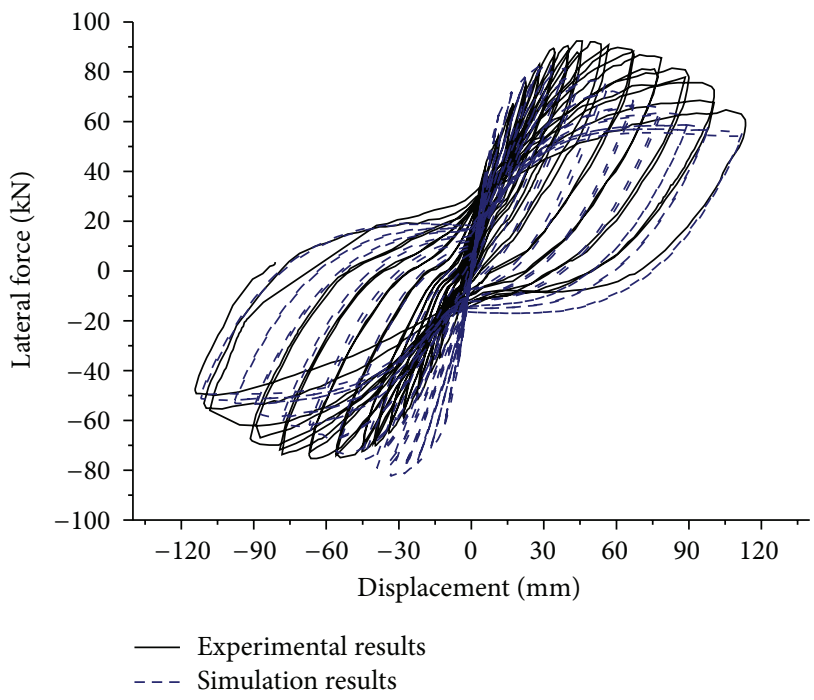

(c)

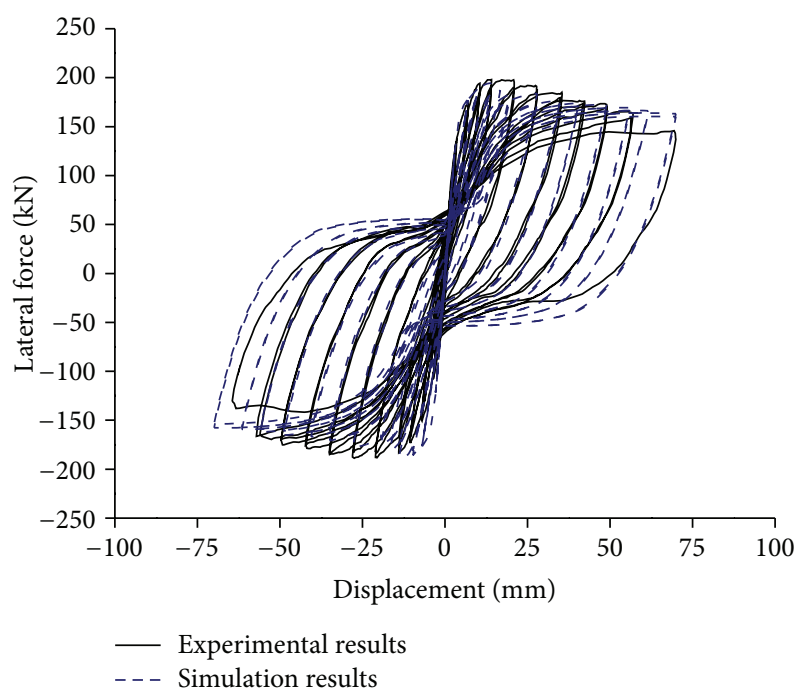

(b)

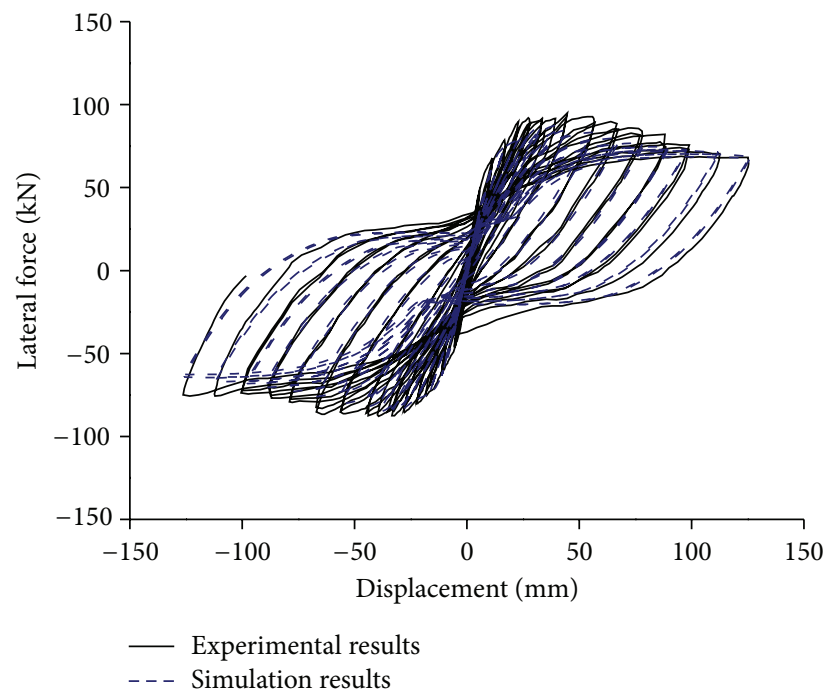

(d)

FIGURE 9: Hysteretic curves comparison of test results with proposed model (a) SU-1, (b) SHG-3, (c) LU-1, and (d) LHG-3.

validation. The test and simulation results of hysteretic behavior are shown in Figure 9. In general, the test data agreed well with the numerical simulation results both along loading paths and unloading paths. Generally, it is noted that OpenSees provides effective method to carry out further studies on seismic performance of hollow RC piers retrofitted with GFRP.

\section{Conclusions}

An experimental and analytical investigation was carried out on the cyclic load responses of GFRP-strengthened RC hollow rectangular bridge piers. A simplified lateral confined model of GFRP is developed by considering effective strength coefficient and area distribution ratio of GFRP sheets. The hysteretic behavior was studied using a fiber element model based on the OpenSees program. Comparing the simulation results and experiment data, the following conclusions can be drawn:

(1) The failure mode, deformation characteristics, and damage position of GFRP-strengthened RC hollow rectangular bridge piers will be changed under strong earthquake excitation. The strengthening hollow rectangular bridge piers with GFRP composite jackets significantly improve the ability of energy dissipation and ductility but not much improvement for the lateral load capacity.

(2) A simplified GFRP-confined concrete model of GFRP developed considering effective strength coefficient and area distribution ratio of GFRP sheets is convenient for application in the confined concrete constitutive model. Based on this lateral confined 
force calculation method in this paper, the results of the force-displacement hysteretic loops agreed well with the experimental data, which validated that the developed simplified model for lateral confined force of hollow rectangular RC bridge piers is effective and accurate.

\section{Conflict of Interests}

The authors declare that they have no conflict of interests regarding the publication of this paper.

\section{Acknowledgments}

This research is jointly funded by the National Natural Science Fund of China (NSFC) (Grants no. 51478022 and no. 51378033), the National Program on Key Basic Research Project (Grant no. 2011CB013600), and the research project of Beijing Municipal Commission of Education (Grant KZ201410005011). Their support is gratefully acknowledged.

\section{References}

[1] Ministry of Communications, JTJ004-89 Specification of Earthquake Resistant Design for Highway Engineering, China Communications Press, Beijing, China, 1990, (Chinese).

[2] H. Qiang, D. Xiuli, L. Jingbo, L. Zhongxian, L. Liyun, and Z. Jianfeng, "Seismic damage of highway bridges during the 2008 Wenchuan earthquake," Earthquake Engineering and Engineering Vibration, vol. 8, no. 2, pp. 263-273, 2009.

[3] Q. Han, X. Du, Y. Zhou, and G. C. Lee, "Experimental study of hollow rectangular bridge column performance under vertical and cyclically bilateral loads," Earthquake Engineering and Engineering Vibration, vol. 12, no. 3, pp. 433-445, 2013.

[4] Y. Shao and A. Mirmiran, "Nonlinear cyclic response of laminated glass FRP tubes filled with concrete," Composite Structures, vol. 65, no. 1, pp. 91-101, 2004.

[5] F. Seible, M. J. N. Priestley, G. A. Hegender, and D. Innamorato, "Seismic retrofit of RC columns with continuous carbon fiber jackets," Journal of Composites for Construction, vol. 1, no. 2, pp. 52-62, 1997.

[6] Y. Xiao and H. Wu, "Compressive behavior of concrete confined by carbon fiber composite jackets," Journal of Materials in Civil Engineering, vol. 12, no. 2, pp. 139-146, 2000.

[7] K. Gajdosova and J. Bilcik, "Full-scale testing of CFRPstrengthened slender reinforced concrete columns," Journal of Composites for Construction, vol. 17, no. 2, pp. 239-248, 2013.

[8] S. A. Guralnick and L. Gunawan, "Strengthening of reinforced concrete bridge columns with FRP wrap," Practice Periodical on Structural Design and Construction, vol. 11, no. 4, Article ID 003604QSC, pp. 218-228, 2006.

[9] C.-T. Cheng, J.-C. Yang, Y.-K. Yeh, and S.-E. Chen, "Seismic performance of repaired hollow-bridge piers," Construction and Building Materials, vol. 17, no. 5, pp. 339-351, 2003.

[10] Y. L. Mo, Y.-K. Yeh, and D. M. Hsieh, "Seismic retrofit of hollow rectangular bridge columns," Journal of Composites for Construction, vol. 8, no. 1, pp. 43-51, 2004.

[11] G. P. Lignola, A. Prota, G. Manfredi, and E. Cosenza, "Experimental performance of RC hollow columns confined with
CFRP," Journal of Composites for Construction, vol. 11, no. 1, pp. 42-49, 2007.

[12] J.-G. Dai, Y.-L. Bai, and J. G. Teng, "Behavior and modeling of concrete confined with FRP composites of large deformability," Journal of Composites for Construction, vol. 15, no. 6, pp. 963973, 2011.

[13] Z. Tao, L.-H. Han, and J.-P. Zhuang, "Axial loading behavior of CFRP strengthened concrete-filled steel tubular stub columns," Advances in Structural Engineering, vol. 10, no. 1, pp. 37-46, 2007.

[14] J. G. Teng and Y. M. Hu, "Behaviour of FRP-jacketed circular steel tubes and cylindrical shells under axial compression," Construction and Building Materials, vol. 21, no. 4, pp. 827-838, 2007.

[15] S. T. Smith, S. Hu, S. J. Kim, and R. Seracino, "FRP-strengthened RC slabs anchored with FRP anchors," Engineering Structures, vol. 33, no. 4, pp. 1075-1087, 2011.

[16] F. Micelli, A. Rizzo, and D. Galati, "Anchorage of composite laminates in RC flexural beams," Structural Concrete, vol. 11, no. 3, pp. 117-126, 2010.

[17] H. W. Zhang, S. T. Smith, and S. J. Kim, "Optimisation of carbon and glass FRP anchor design," Construction and Building Materials, vol. 32, pp. 1-12, 2012.

[18] N. Attari, S. Amziane, and M. Chemrouk, "Flexural strengthening of concrete beams using CFRP, GFRP and hybrid FRP sheets," Construction and Building Materials, vol. 37, pp. 746757, 2012.

[19] T. Ozbakkaloglu and M. Saatcioglu, "Seismic behavior of high-strength concrete columns confined by fiber-reinforced polymer tubes," Journal of Composites for Construction, vol. 10, no. 6, pp. 538-549, 2006.

[20] Y. Idris and T. Ozbakkaloglu, "Seismic behavior of highstrength concrete-filled FRP tube columns," Journal of Composites for Construction, vol. 17, no. 6, Article ID 04013013, 2013.

[21] M. J. N. Priestley, Seismic Design and Retrofit of Bridges, John Wiley \& Sons, 1996.

[22] M. Menegotto and P. E. Pinto, "Method of analysis for cyclically loaded reinforced concrete plane frames including changes in geometry and non-elastic behavior of elements under combined normal force and bending," in Proceedings of the IABSE Symposium on the Resistance and Ultimate Deformability of Structures Acted on by Well-Defined Repeated Loads, Lisbon, Portugal, 1973.

[23] J. B. Mander, M. J. N. Priestley, and R. Park, "Theoretical stress-strain model for confined concrete," Journal of Structural Engineering, vol. 114, no. 8, pp. 1804-1826, 1988. 

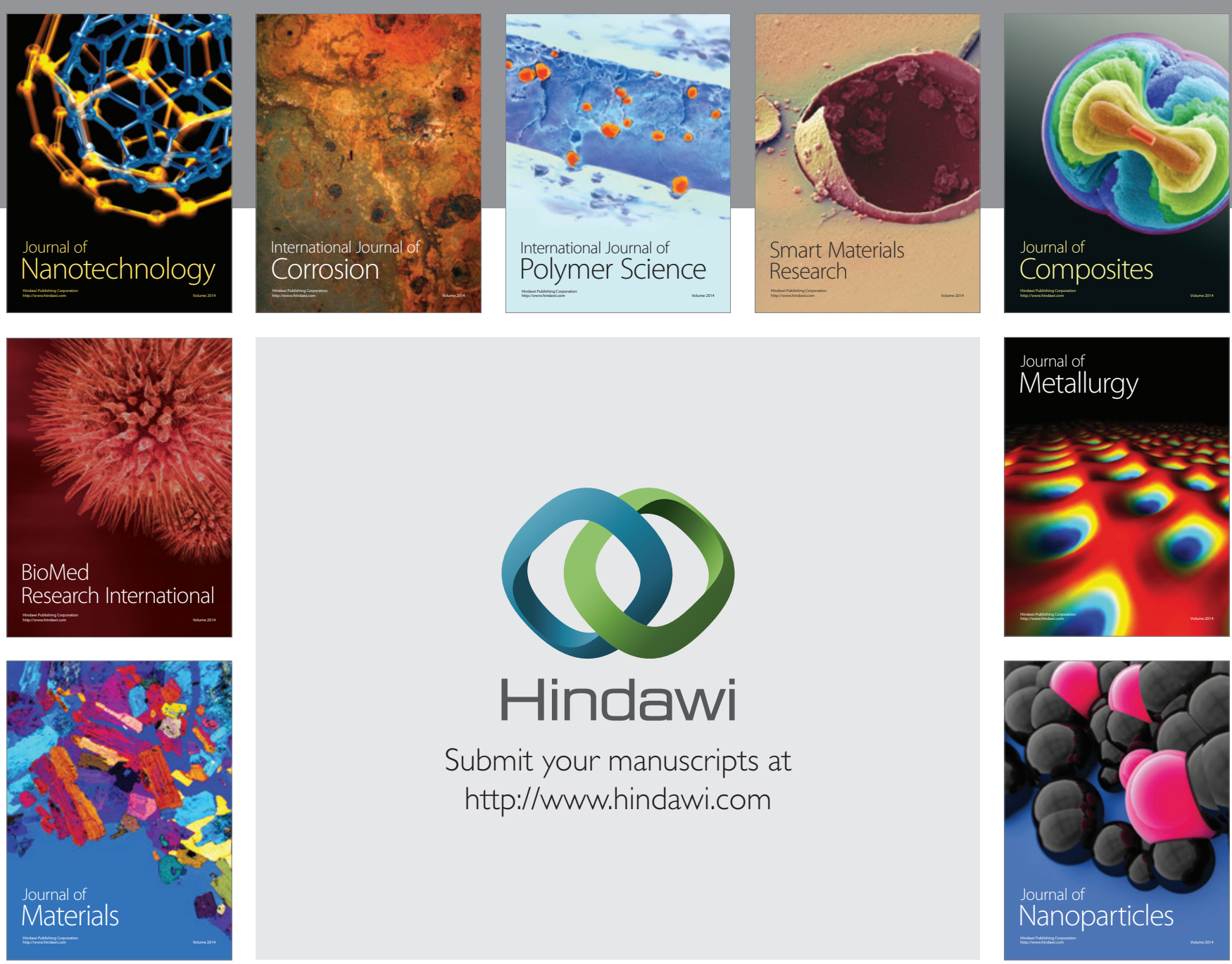

Submit your manuscripts at http://www.hindawi.com
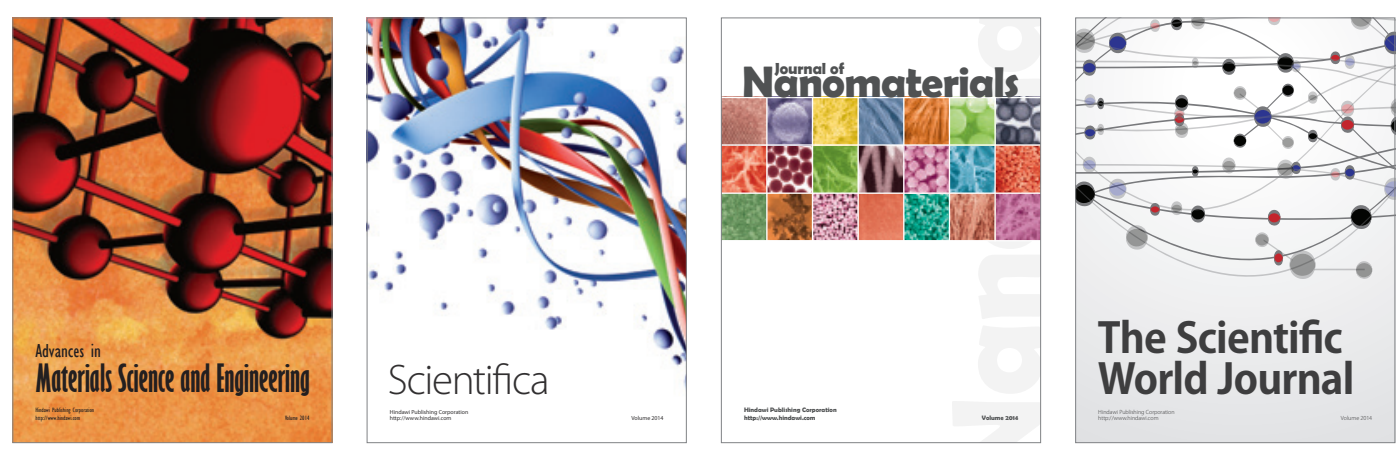

\section{The Scientific World Journal}
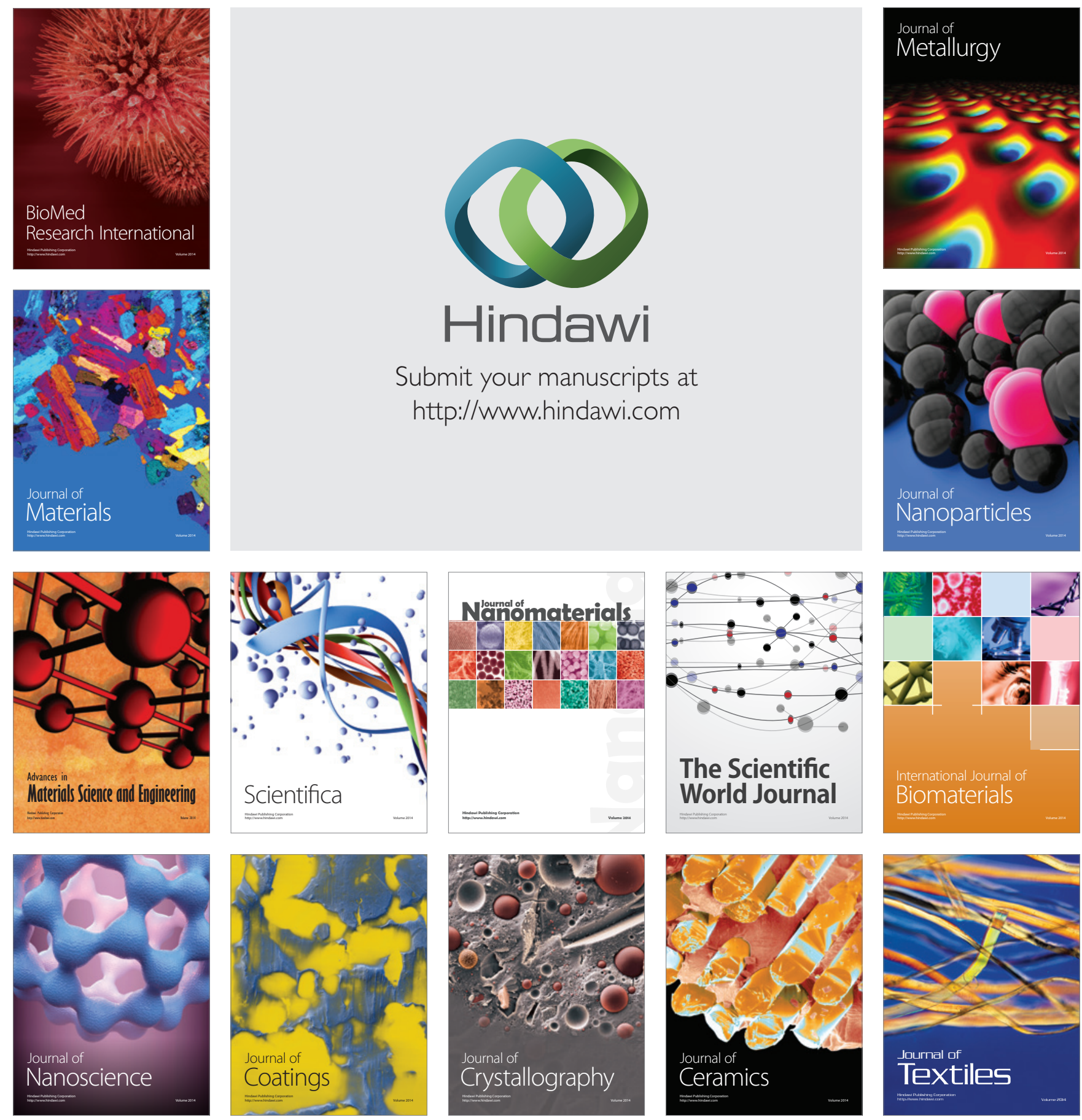